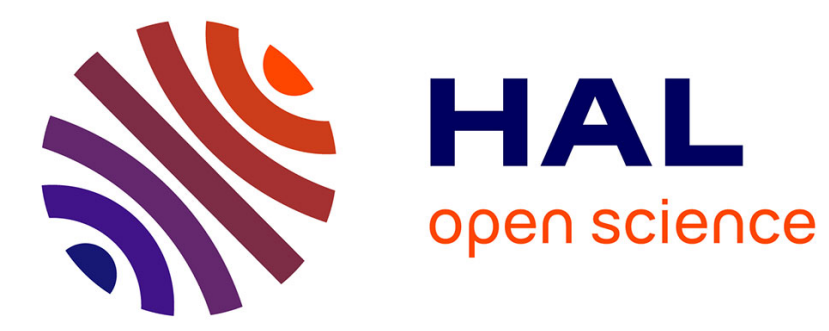

\title{
LOW FREQUENCY PHONONS IN SINTERED COPPER
}

\author{
B. Frisken, F. Guillon, J. Harrison, J. Page
}

\section{To cite this version:}

B. Frisken, F. Guillon, J. Harrison, J. Page. LOW FREQUENCY PHONONS IN SINTERED COPPER. Journal de Physique Colloques, 1981, 42 (C6), pp.C6-858-C6-860. 10.1051/jphyscol:19816254 . jpa-00221342

\section{HAL Id: jpa-00221342 https://hal.science/jpa-00221342}

Submitted on 1 Jan 1981

HAL is a multi-disciplinary open access archive for the deposit and dissemination of scientific research documents, whether they are published or not. The documents may come from teaching and research institutions in France or abroad, or from public or private research centers.
L'archive ouverte pluridisciplinaire HAL, est destinée au dépôt et à la diffusion de documents scientifiques de niveau recherche, publiés ou non, émanant des établissements d'enseignement et de recherche français ou étrangers, des laboratoires publics ou privés. 


\title{
LOW FREQUENCY PHONONS IN SINTERED COPPER
}

\author{
B. Frisken, F. Guillon, J.P. Harrison and J.H. Page \\ Physics Department, Queen's University, Kingston, Ontario, Canada, K7L $3 N 6$
}

\begin{abstract}
Measurements of Young's Modulus and sound velocity of a range of sintered copper powder samples have demonstrated the existence of low frequency soft phonon modes that could explain the low temperature anomaly in the Kapitza resistance between 1 iquid ${ }^{3} \mathrm{He}$ and sintered metal heat exchangers below $10 \mathrm{mk}$.
\end{abstract}

Introduction. All measurements of the Kapitza resistance, or thermal boundary resistance, between 1iquid ${ }^{3} \mathrm{He}$ and solids in the region of $1 \mathrm{mK}$ have been anomalously small when compared with the predictions of acoustic theory. In addition, the measured resistances have generally been proportional to $\mathrm{T}^{-1}$ rather than $\mathrm{T}^{-3}$ as given by acoustic theory ${ }^{(1)}$. This is a low temperature effect since the acoustic theory seems to describe experimental results quite well in the 30-100 mK temperature range. Either there 13 an extra channel for heat flow across the boundary or there is a problem with the acoustic theory when $\mathrm{T} \leqslant 10 \mathrm{mK}$. It has been argued by others that magnetic coupling is the extra channel. However, this is unlikely since the anomalous resistance is independent of magnetic field, ${ }^{3} \mathrm{He}$ pressure, phase of the ${ }^{3} \mathrm{He}$ (A, B or normal) or magnetic impurity content of the solfd. We are instead pursuing the possibility that the usual acoustic mismatch theory is inappropriate at the lowest temperatures for the solids that have been investigated; all experiments have been made with solids that were efther sintered metal powders or powdered cerium magnesium nitrate. In all cases the powder diameter (d) was smaller than or comparable with the dominant phonon wavelength at $1 \mathrm{mK}$ ( $30 \mu \mathrm{m}$ in bulk solids). Therefore the usual Debye spectrum has a long wavelength cut-off at $\lambda_{\text {ph }} \sim d$, with a consequent low energy cut-off at $E / k_{B} \sim h v_{D} / k_{B} d(\sim 100 \mathrm{mK}$ when $d=1 \mu m)$ where $k_{B}$ is Boltzmann's constant and $v_{D}$ is the Debye sound velocity. A consequence is that essentially no bulk phonons are excited at $1 \mathrm{mk}$. Instead there should be new normal modes associated with the powder particles as lumped masses and the necks between particles as weak springs. We present here the results of an investigation of these new modes.

Sample Preparation. A variety of copper and silver powder diameters, packing factors and sintering processes have been used by various groups in the past (1). Th1s work was done with $700 \&$ copper powder ${ }^{(2)}$ and with a range of packing factors and sintering temperatures. The powder was first cleaned in trichloroethylene and then in 
acetone (10 minutes in an ultrasonic bath). The powder was dried, placed loosely in aluminum foll boats in a fumace tube and the tube evacuated. When the pressure had dropped to $10^{-4}$ torr the furnace was switched on and brought up to its working temperature (usually $200^{\circ} \mathrm{C}$ ). Then hydrogen was allowed to stream through the cube for 15 minutes at which time the fumace tube was quickly cooled. As soon as possible the pre-sintered powder was packed into a clean mold. Apart from varying the sinter temperature the sinter process was the same as the pre-sinter process described above. The final samples were in the form of 2 thick discs or beams $70 \times 5$ m x $2 \mathrm{~mm}$.

Method and Results. In order to investigate the low frequency modes, measurements were made of the Young's modulus (zero frequency) and the velocity of longitudinal sound (15 MHz).

(1) Young's Modulus. The sinters are quite stiff and to obtain a measurable distortion with reasonable loads the sinter was formed into long thin beams that were supported at the ends and loaded in the centre. The beams were loaded in $2 \mathrm{gm}$ increments to about $40 \mathrm{gm}$ and then unloaded in increments while the deformations were measured with a travelling microscope. Young's Modulus $(Y)$ was determined from a deformation versus load plot. The results are shown in figure 1 , plotted as $\mathrm{Y} / \mathrm{Y}_{\mathrm{cu}}$ where $\mathrm{Y}_{\mathrm{cu}}$ is the Young's modulus of copper $\left(12.5 \times 10^{10} \mathrm{Nm}^{-2}\right)$. (ii) Sound Velocity. The ultrasonic velocity was measured in the frequency range 12-20 MHz on thin disc-shaped samples. The sinters were dry polished flat and parallel using fine silfcon carbide paper. The samples were then placed between two quartz delay rods and the velocity was measured from the cime delay between a reflected pulse, which has travelled up and down the quartz rod only, and a transmitted pulse, which has passed through the specimen and each quartz rod. The transmitted signals were generally weak and often broad, in part due to interference effects caused by inhomogeneities in the sinters, and consequently the leading edge of the pulses was used in all measurements. To prevent bonding fluld from penetrating the pores of the sinter thin latex membranes were inserted between the sinter and the quartz rod, with a layer of Nonaq stopcock grease or glycerol between the quartz and the membrane but not between the membrane and the sinter. A measured correction of $0.07 \mu$ s was applied for the delay in the membranes. The technique worked well for both $\mathrm{Ag}$ and $\mathrm{Cu}$ sinters over a range of packing factors $\mathrm{f}$; for a $\mathrm{Ag}$ sinter with $f=55 \%$, we obtain the velocity $v_{\ell}=(1.73 \pm .05) \times 10^{3} \mathrm{~ms}^{-1}$ and for $\mathrm{Cu}$ sinters with $\mathrm{f}=48 \%$ and $42 \%$ we measure $v_{\ell}=(1.6 \pm .1)$ and $(1.2 \pm .2) \times 10^{3} \mathrm{~ms}^{-1}$ respectively. Measurements were also made on a $\mathrm{Cu}$ sinter of $33 \%$ filling factor, but even with the sample thickness reduced to $0.53 \mathrm{~m}$, the uitrasonic attenuation was so great that the membranes had to be removed for a transmitted signal to be observed; In this case, the bond was made with Nonag which is sufficiently viscous to cause minimal contamination in the sinter. For this sample $v_{\ell}=0.75( \pm .2) \times 10^{3} \mathrm{~ms}^{-1}$. The results for these samples have been converted to a reduced elastic modulus $\rho v_{\ell}{ }^{2} /\left(\rho v_{\ell}{ }^{2}\right)$ bulk where bulk refers to bulk copper or silver. 
Discussion of Results. First of all the sinters are elastic and considerably softer than bulk copper. There is a marked, but not unexpected ${ }^{(3)}$, dependence upon packing factor. This has been confirmed in more recent work on both copper and silver (4). The sound velocity and elastic modulus measurements are in satisfactory agreement; the agreement is better in the more recent work in which sample preparation was more consistent.

For these soft modes to be significant in heat transfer at $\leqslant 10 \mathrm{mK}$ they would have to exist to $v>10^{-2}\left(k_{B} / h\right)$ or $200 \mathrm{MHz}$. Their upper limit can in fact be estimated by applying Debye theory. With $\mathrm{N} / \mathrm{V} \sim 10^{18} \mathrm{~m}^{-3(4)}$ we find $v_{\mathrm{D}} \sim 500 \mathrm{MHz}$. Therefore these modes should completely dominate the phonon spectrum below $10 \mathrm{mk}$. They are softer modes and have a density of states up by 250 when compared to bulk copper and it is not surprising therefore that acoustic mismatch theory with bulk copper parameters falls to agree with experimental results.

In conclusion it is emphasised that these are continuum modes of the sinter plus whatever occupies the pores (usually liquid helium). For a full understanding of heat transfer below $10 \mathrm{mK}$ a study is now required of the coupling of these modes to the electron gas in the metal and to the quasiparticle excitations in the 1fquid ${ }^{3} \mathrm{He}$ or ${ }^{3} \mathrm{He} /{ }^{4} \mathrm{He}$ mixtures.

Acknowledgements. This work has been supported by N.S.E.R.C. and by C.R.A.D. Of the B.N.D. We would like to thank John Robertson for preparing the samples used for the sound velocity measurements and Christian Frénois for assistance with some of the velocity measurements.

1. Detailed references are given in the review article: J,P. Harrison, J. Low Temp. Phys. 37, 467 (1979).

2. Ul-Vac Vacuum Metallurgical Co. Ltd., Tokyo, Japan.

3. David Wood (private communicarion), E. Domany, J.A. Gubernatis and

J.A. Krumhans1, Journal of Geophysical Research 80, 485 (1975).

4. J. Robertson, F. Guillon and J.P. Harrison (to be published).

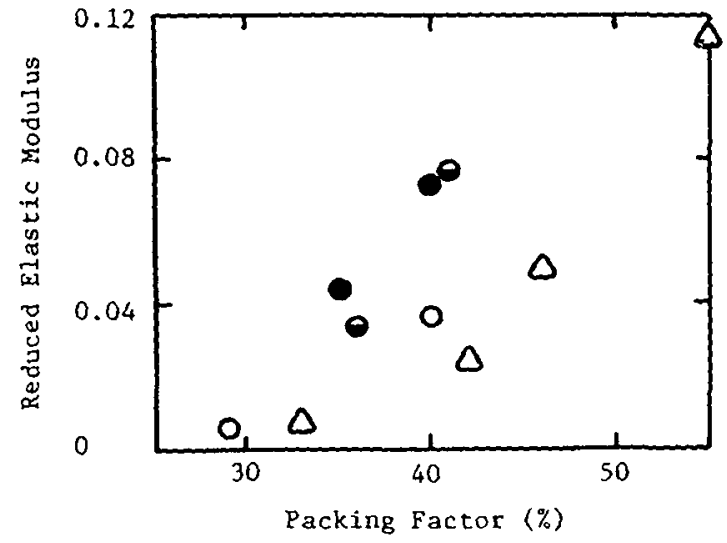

Figure 1. Circles are the beam bending results with sintering temperatures as follows: Open circles, $175^{\circ} \mathrm{C}$ Half-open clrcles, $200^{\circ} \mathrm{C}$ closed circles, $225^{\circ} \mathrm{C}$.

Triangles are the sound velocity results with a sintering temperature of $200^{\circ} \mathrm{C}$. The $55 \%$ result is for silver. 